Article

\title{
Improvement of Hargreaves-Samani Reference Evapotranspiration Estimates with Local Calibration
}

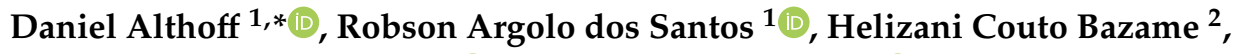 \\ Fernando França da Cunha ${ }^{1} \mathbb{D}$ and Roberto Filgueiras ${ }^{1} \mathbb{D}$ \\ 1 Department of Agricultural Engineering, Federal University of Viçosa (UFV), Avenue Peter Henry Rolfs, \\ Viçosa 36570-900, Minas Gerais, Brazil; robson.argolo@ufv.br (R.A.d.S.); fernando.cunha@ufv.br (F.F.d.C.); \\ roberto.f.filgueiras@ufv.br (R.F.) \\ 2 Biosystems Engineering Department, Luiz de Queiroz College of Agriculture (ESALQ), \\ University of São Paulo (USP), Avenue Pádua Dias, n¹1, Piracicaba-SP 13418-900, Brazil; \\ helizanicouto@usp.br \\ * Correspondence: daniel.althoff@ufv.br; Tel.: +55-31-3612-4004
}

Received: 8 September 2019; Accepted: 26 October 2019; Published: 30 October 2019

check for updates

\begin{abstract}
Improving irrigation water management is an important asset when facing increased water shortages. The Hargreaves-Samani (HS) method is a simple method that can be used as an alternative to the Penman-Monteith (PM) method, which requires only temperature measurements for estimating reference evapotranspiration (ETo). However, the applicability of this method relies on its calibration to local meteorological specificities. The objective of this study was to investigate the effects of local calibration on the performance of the HS equation. The study was carried out for the middle portion of the São Francisco River Basin (MSFB), Brazil, and considered four calibration approaches: A1—single calibration for the entire MSFB; A2—separate calibration by clusters of months; A3 - by clusters of stations; and A4-for all contexts resulting by combining A2 and A3. Months from the wet season showed larger improvements by the calibration of the HS model, since mean air temperature and its daily range showed stronger correlations to ETo. On the other hand, the months from the dry season and stations from the eastern region of MSFB performed poorly regardless of the calibration approach adopted. This occurred because, in those cases, ETo presented larger correlation to variables that are missing in the HS equation, and the use of the full PM equation seems unavoidable.
\end{abstract}

Keywords: agrometeorology; biomes transition; data clustering; k-means; Penman-Monteith

\section{Introduction}

The severity of water shortage due to increasing demands for inputs is an important issue of socioeconomic and global sustainability [1]. In this context, Brazil is one of the few countries that is able to increase its productivity in a sustainable way [2]; however, despite the water abundance, most of this resource is available in less populated areas. Its heterogeneous distribution results in conflicts over its use being more common than expected. These disputes arise mainly due to the insufficient amount of water to supply for humans and animals [3]. In the Brazilian Northeast, this problem is commonly related to lower rainfall rates and the large amount of water withdrawn by irrigation activities [4].

Irrigation provides water and better growth conditions to crops, resulting in higher yields [5]. Despite being an intensive water use activity, irrigation is one of the main activities responsible for guaranteeing food security for future generations [6]. However, in order to attain the benefits of this activity, it is fundamental to observe criteria such as the economic and environmental integrity [7]. The proper management of irrigation reduces the consumption of electricity, increases the efficiency of 
water use and boosts agricultural productivity $[8,9]$. In addition, adequate management strategies reduce water withdrawn from streams and, consequently, reduce the conflicts with the local community.

Irrigation management via climate is widely studied and applied [10-14], especially due to its practicality in large-scales and economic viability. In order to carry out the irrigation management via climate, the amount of water to be supplied to irrigated crops is calculated as a function of the product between the reference evapotranspiration (ETo) and the coefficients associated with crop and soil [10]. However, the quantification of ETo in a representative manner depends on the availability of reliable meteorological data, as well as the adequate use of methodologies for its estimation.

The Penman-Monteith (PM) method is widely used as the standard for estimating ETo [10,15]. This method is based on physical processes and incorporates an aerodynamic term, the energy balance and physiological parameters. Its calculation depends on the acquisition of several meteorological variables as input, which is costly. Therefore, data may not be available or not in range for farmers in remote areas. In this case, the paper 56 from the Food and Agriculture Organization of the United Nations (FAO-56) [10] recommends the use of the Hargreaves-Samani (HS) model [16]. The advantage that this method offers is the need to only measure one input variable, the air temperature. However, empirical limitations and lower performance of simplified methods make it necessary to calibrate them to the localities of interest, as well as the development of strategies that allow greater efficiency in irrigation management.

Several authors have proposed the calibration of the empirical equation of ETo considering as reference, the PM model [17-20]. The regional calibration is an alternative that aims to improve the performance of ETo estimation, allowing its use in several locations and under different climatic conditions $[17,21,22]$. Besides these methods, other authors have proposed different forms of calibration for better performance. Aguilar and Polo [23] proposed the calibration of the equation considering the dry and rainy seasons. Cobaner et al. [11] included the wind speed variable to the simple linear regression used in the calibration. Zanetti et al. [24] used different calibration methodologies, from using simple linear regression to segregating the stations in groups that presented the same climatic type and thermal amplitude class. Regarding more complex techniques used to estimate ETo, such as machine learning models, Reis et al. [25] developed models calibrated for each station and for pooled data from all weather stations used. Ferreira et al. [13] clustered stations by similar climatic characteristics prior to calibrating their models.

Literature provides evidence that both the spatial and temporal dynamics of meteorological variables can be decisive in improving the HS performance. Therefore, comprehending these implications in evapotranspiration is fundamental to understand the water balance of the agro-ecosystem [26] and to develop more efficient calibration techniques for methodologies demanding fewer input variables.

In this context, the objective of the present study was to investigate the spatial and temporal dynamics of meteorological data and their implications in the calibration of the HS model.

\section{Materials and Methods}

\subsection{Study Area}

The area of this study comprises the middle portion of the São Francisco River Basin (MSFB) (Figure 1). The middle of São Francisco occupies about $402,500 \mathrm{~km}^{2}$, representing $63 \%$ of the entire São Francisco River Basin. The climate of the region is tropical semi-arid and dry sub-humid, with rainfall ranging from $600 \mathrm{~mm}$ to $1400 \mathrm{~mm}$, average annual temperatures around $24^{\circ} \mathrm{C}$ and an average evapotranspiration of $1300 \mathrm{~mm}$ [27]. 


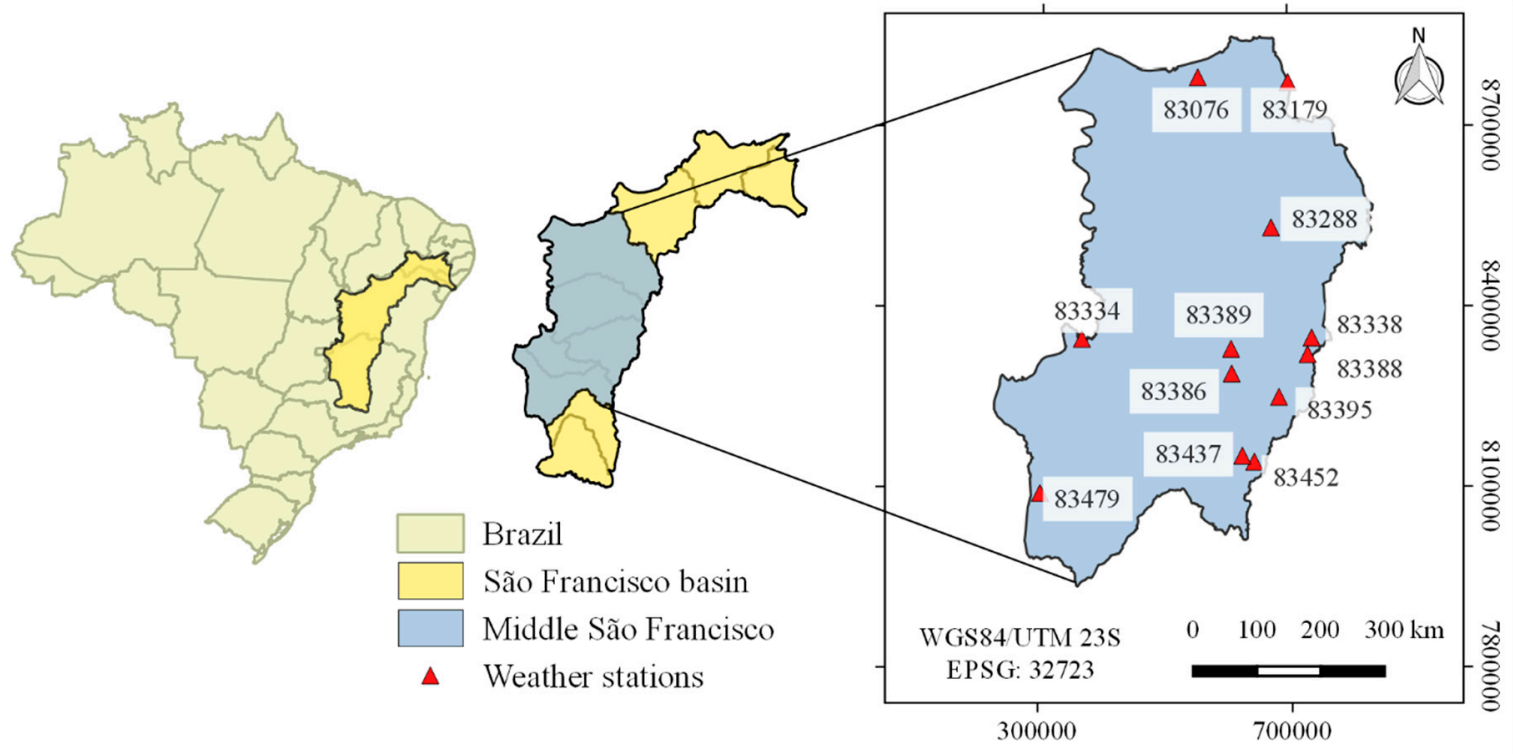

Figure 1. Location of study area and weather stations in relation to the São Francisco Basin and Brazil.

Since it is an extensive area, there is great diversity in terms of climate, types of soils, vegetation and agricultural use. The region is characterized by the transition between three biomes, the Cerrado, Caatinga and Atlantic rainforest (Figure S1), with predominant dry land and savannah-like vegetation. The region is marked for extensive irrigated perimeters [28,29], cultivating banana, mango, citrus, grape, sugar cane, soybean, corn, cotton and coffee [30].

\subsection{Weather Station Data Used}

The data used referred to daily observations from 12 conventional weather stations (Table 1) covering the period from 1997 to 2016. All stations were located in the study area and their data were obtained from the Meteorological Database for Education and Research (BDMEP), made available by the National Institute of Meteorology (INMET) of Brazil.

Table 1. Weather stations information.

\begin{tabular}{cccccc}
\hline Municipality & State & WMO $^{*}$ & Latitude & Longitude & Altitude (m) \\
\hline Barra & BA & 83179 & $-11.08^{\circ}$ & $-43.16^{\circ}$ & 402 \\
Bom Jesus da Lapa & BA & 83288 & $-13.26^{\circ}$ & $-43.41^{\circ}$ & 440 \\
Espinosa & MG & 83338 & $-14.91^{\circ}$ & $-42.80^{\circ}$ & 570 \\
Formoso & MG & 83334 & $-14.93^{\circ}$ & $-46.25^{\circ}$ & 840 \\
Janaúba & MG & 83395 & $-15.80^{\circ}$ & $-43.29^{\circ}$ & 516 \\
Januária & MG & 83386 & $-15.45^{\circ}$ & $-44.00^{\circ}$ & 474 \\
Juramento & MG & 83452 & $-16.77^{\circ}$ & $-43.66^{\circ}$ & 648 \\
Mocambinho & MG & 83389 & $-15.08^{\circ}$ & $-44.01^{\circ}$ & 452 \\
Monte Azul & MG & 83388 & $-15.16^{\circ}$ & $-42.86^{\circ}$ & 625 \\
Montes Claros & MG & 83437 & $-16.68^{\circ}$ & $-43.84^{\circ}$ & 652 \\
Paracatu & MG & 83479 & $-17.24^{\circ}$ & $-46.88^{\circ}$ & 712 \\
Santa Rita de & BA & 83076 & $-11.01^{\circ}$ & $-44.51^{\circ}$ & 450 \\
Cássia & & & & \\
\hline
\end{tabular}

* Weather stations ID according to the World Meteorological Organization (WMO).

The information acquired by the weather stations were mean $\left(\mathrm{T},{ }^{\circ} \mathrm{C}\right)$, maximum $\left(\mathrm{T}_{\max },{ }^{\circ} \mathrm{C}\right)$ and minimum air temperature $\left(\mathrm{T}_{\min },{ }^{\circ} \mathrm{C}\right)$; relative humidity $(\mathrm{RH}, \%)$; wind speed $10 \mathrm{~m}$ above ground $\left(\mathrm{u}_{10}, \mathrm{~m} \cdot \mathrm{s}^{-1}\right)$; and duration of sunshine hours in a day $(\mathrm{n})$. Sunshine hours and the wind speed were 
later converted to solar radiation (Rs, MJ.m ${ }^{-2} \cdot$ day $\left.^{-1}\right)$ and wind speed $2 \mathrm{~m}$ above ground $\left(\mathrm{u}_{2}, \mathrm{~m} \cdot \mathrm{s}^{-1}\right)$, following the methodology proposed by Allen et al. [10].

The data obtained were evaluated to eliminate faulty data, e.g., number of hours of sunshine above the observable limit, negative wind speed [31], relative humidity outside the range of $5 \%$ to $100 \%$ [32] and values of minimum temperature higher than the maximum temperature [33].

\subsection{Reference Evapotranspiration}

\subsubsection{Penman-Monteith}

The Penman-Monteith grass reference evapotranspiration method standardized by FAO [10] was used as a base for comparison and subsequent fit of the Hargreaves-Samani method. The Penman-Monteith equation is written as follows:

$$
\mathrm{ETo}=\frac{0.408\left(\mathrm{R}_{\mathrm{n}}-\mathrm{G}\right)+\gamma \frac{900}{\mathrm{~T}+273} \mathrm{u}_{2}\left(\mathrm{e}_{\mathrm{s}}-\mathrm{e}_{\mathrm{a}}\right)}{\Delta+\gamma\left(1+0.34 \mathrm{u}_{2}\right)}
$$

where: $\mathrm{ETo}=$ reference evapotranspiration $\left(\mathrm{mm} \cdot \mathrm{day}^{-1}\right) ; \mathrm{R}_{\mathrm{n}}=$ net radiation $\left(\mathrm{MJ} \cdot \mathrm{m}^{-2} \cdot \mathrm{day}^{-1}\right) ; \mathrm{G}=$ soil heat flux $\left(\mathrm{MJ} \cdot \mathrm{m}^{-2} \cdot \mathrm{day}^{-1}\right) ; \mathrm{T}=$ mean air temperature $\left({ }^{\circ} \mathrm{C}\right) ; \mathrm{u}_{2}=$ wind speed $2 \mathrm{~m}$ above ground $\left(\mathrm{m} \cdot \mathrm{s}^{-1}\right)$; $\mathrm{e}_{\mathrm{s}}=$ saturation vapor pressure $(\mathrm{kPa}) ; \mathrm{e}_{\mathrm{a}}=$ actual vapor pressure $(\mathrm{kPa}) ; \Delta=$ slope of saturation vapor pressure curve $\left(\mathrm{kPa} \cdot{ }^{\circ} \mathrm{C}^{-1}\right)$; and, $\gamma=$ psychrometric constant $\left(\mathrm{kPa} \cdot{ }^{\circ} \mathrm{C}^{-1}\right)$. All the parameters from Equation (1) were computed according to Allen et al. [10].

\subsubsection{Hargreaves-Samani}

In order to estimate ETo considering only temperature measurements, we used the Hargreaves-Samani equation [16] as follows:

$$
\mathrm{ETo}=0.0023\left(\mathrm{~T}_{\max }-\mathrm{T}_{\min }\right)^{0.5}(\mathrm{~T}+17.8) \mathrm{Ra}
$$

where: $\mathrm{Ra}=$ extraterrestrial radiation $\left(\mathrm{mm} \cdot \mathrm{day}^{-1}\right)$. Extraterrestrial radiation was calculated from the latitude and day data of the year [10], and no equipment was needed for its measurement.

The coefficients adopted in the HS equation present an empirical basis, calibrated for Davis, in California. Thus, calibrating Equation (2) is necessary in order to adequately implement this equation for regions of interest.

\subsection{Improving Hargreaves-Samani Estimates}

A few different approaches were considered in the calibration of the Hargreaves-Samani: A1-general calibration of coefficients for the entire MSFB region and year; A2 - separate calibration for clusters of months; A3-separate calibration for clusters of stations (subregions); A4-separate calibration in the contexts that resulted from clustering months within subregions, a combination of approaches A2 and A3.

\subsubsection{General Calibration of Coefficients}

In order to calibrate the Hargreaves-Samani empirical coefficients, we must respect the form in which the equation was developed. For instance, in the absence of sunshine hours or solar radiation observation, Hargreaves and Samani [34] adopted the concept that the difference between maximum and minimum air temperature $\left(\mathrm{TR}=\mathrm{T}_{\max }-\mathrm{T}_{\min }\right)$ can be used to estimate the fraction of extraterrestrial radiation reaching the Earth's surface [10] (Equation (3)).

$$
\mathrm{Rs}=\mathrm{k}_{\mathrm{Rs}}\left(\mathrm{T}_{\max }-\mathrm{T}_{\min }\right)^{0.5} \mathrm{Ra}
$$


where $\mathrm{k}_{\mathrm{Rs}}=$ empirical coefficient fitted to $\mathrm{Rs} / \mathrm{Ra}\left({ }^{\circ} \mathrm{C}^{-0.5}\right)$. The original form or the Hargreaves-Samani equation (Equation (2)) adopts $k_{\mathrm{Rs}}$ equal 0.17, but was here calibrated considering all observations for the middle of São Francisco.

The mean air temperature offset ("17.8" in Equation (2)) was also calibrated considering the fitted value of $k_{R s}$. Thus, for the general adjustment of the Hargreaves-Samani coefficients, the equation may be written as:

$$
\mathrm{ETo}=0.0135 \mathrm{k}_{\mathrm{Rs}}\left(\mathrm{T}_{\max }-\mathrm{T}_{\min }\right)^{0.5}(\mathrm{~T}+\text { offset }) \mathrm{Ra}
$$

where offset $=$ mean air temperature offset.

\subsubsection{Regional or Seasonal Clustering of Data}

There is evidence in the literature indicating that both seasonal $[23,24]$ and spatial [13] patterns of meteorological variables may influence the performance of predictions made by methods simple in input requirement. Therefore, in an attempt to better calibrate the HS equation for the region, we investigated the effects of clustering data by spatial and seasonal similarities.

The investigation was carried out using the k-means algorithm [35] to check for groups of months or stations which presented similar correlation between meteorological parameters and reference evapotranspiration. Therefore, we used as input for the algorithm, the linear correlation between Penman-Monteith reference evapotranspiration (EToPM) and meteorological parameters ( $\mathrm{T}$, TR and Ra). This was performed considering all linear correlations by month and station. The decision on the beneficial effects of separating data into groups of months or stations was based in the optimal numbers of cluster by (i) the total within-cluster sum of squares and by (ii) the average silhouette width method [36].

The total within-cluster sum of squares method is based on observing the decrease of total within-cluster sum of squares by increasing the number of clusters; the optimal number of clusters is chosen when the decrease rate becomes less steep ("elbow method") [37]. The average silhouette method, on the other hand, measures how similar an object is to its own cluster (cohesion) compared to other clusters (separation). The average silhouette values range from -1 to +1 , where positive values closer to 1 indicate good cohesion and separation, and negative values are undesired for clustering.

\subsection{Validation and Accuracy Indicators}

The data was temporally split into calibration $(70 \%)$ and test set $(30 \%)$. That is, using observations from 01-01-1997 to 31-12-2010 (14 years) as calibration data and observations from 01-01-2011 to 31-12-2016 (six years) as a test set. The performance of the proposed approaches was evaluated by comparing their predictions for the test set to corresponding ETopM values. Performance was measured with several criteria:

1. The slope of the regression forced to the origin (FTO) considering EToPM as observed data $\left(\mathrm{O}_{\mathrm{i}}\right)$ and $\mathrm{ETo}_{\mathrm{HS}}$ as predicted values $\left(\mathrm{P}_{\mathrm{i}}\right)$.

2. Coefficient of determination $\left(\mathrm{R}^{2}\right)$ of the ordinary least squares (OLS) regression considering $\mathrm{O}_{\mathrm{i}}$ and $P_{i}$.

3. Mean bias error $\left(\mathrm{ME}, \mathrm{mm} \cdot \mathrm{day}^{-1}\right)$, mean absolute error $\left(\mathrm{MAE}, \mathrm{mm} \cdot \mathrm{day}^{-1}\right.$ ) and root mean square error (RMSE, $\left.\mathrm{mm} \cdot \mathrm{day}^{-1}\right)$.

Slopes of the FTO regression close to 1.0 indicate that $\mathrm{ETo}_{\mathrm{PM}}$ and $\mathrm{ETo}_{\mathrm{HS}}$ are similar, while values $>1.0$ suggest overestimation, and $<1.0$ underestimation. The $\mathrm{R}^{2}$ of the OLS regression indicates how much of the variation of $\mathrm{ETO}_{\mathrm{PM}}$ is explained by the variation of $\mathrm{ETo}_{\mathrm{HS}}$. ME indicates the average under or overestimation, MAE indicates the average magnitude of absolute errors and RMSE is used as a 
measure of dispersion, giving higher importance to larger errors. The statistical indices are described in Equations (5)-(8):

$$
\begin{gathered}
\text { ME }=\frac{1}{n} \sum_{i=1}^{n}\left(P_{i}-O_{i}\right) \\
\text { MAE }=\frac{1}{n} \sum_{i=1}^{n}\left|P_{i}-O_{i}\right| \\
\text { RMSE }=\sqrt{\frac{1}{n} \sum_{i=1}^{n}\left(P_{i}-O_{i}\right)^{2}} \\
R^{2}=\frac{\left[\sum_{i=1}^{n}\left(P_{i}-\bar{P}\right)\left(O_{i}-\bar{O}\right)\right]^{2}}{\sum_{i=1}^{n}\left(P_{i}-\bar{P}\right)^{2} \sum_{i=1}^{n}\left(O_{i}-\bar{O}\right)^{2}}
\end{gathered}
$$

where: $\mathrm{O}_{\mathrm{i}}=$ observed/calculated ETo for the test set $(\mathrm{EToPM})$ and, $\mathrm{P}_{\mathrm{i}}=$ predicted ETo for the test set $\left(\mathrm{ETo}_{\mathrm{HS}}\right)$.

\section{Results and Discussion}

\subsection{Data Analyses}

Rainfall from weather stations and observed well-defined wet and dry seasons (Figure S2). The months from May to September were considered in this study as the dry season, for they presented close to no rainfall for all stations and altogether represented only $3.4 \%$ of the total annual rainfall. April and October characterized the transition periods from and to wetter months, with monthly rainfall usually above $50 \mathrm{~mm} \cdot \mathrm{month}^{-1}$. Other meteorological parameters for each station are presented on Figures S3-S8, while a general overview on the region is shown in Figure 2.
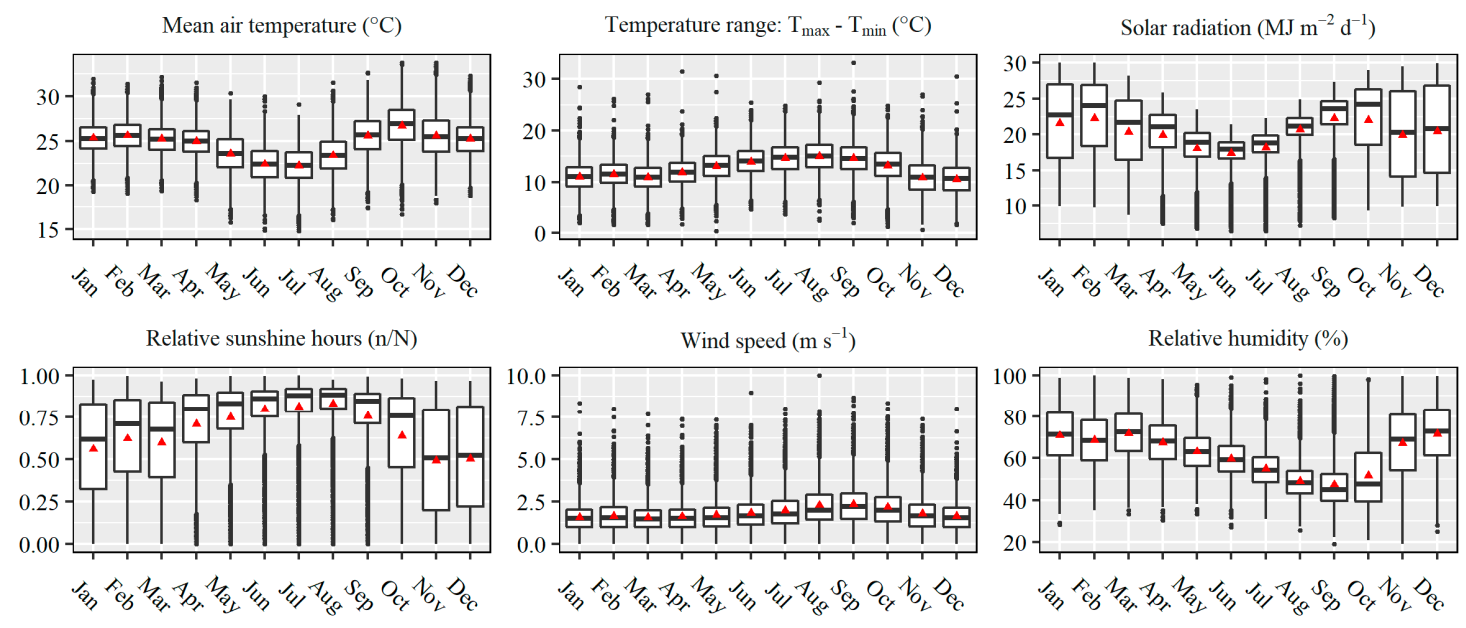

Figure 2. Descriptive statistics of meteorological parameters for the middle São Francisco from 1997 to 2016.

In Figure 2, we notice that there is an evident seasonality to the data. Temperature presents its lower values in winter, but with higher temperature ranges. Higher temperature ranges coincide with the drier period, the behavior of which is well described by Allen et al. [10]. Fewer clouds occur during the dry season, resulting in higher relative sunshine hours $(\mathrm{n} / \mathrm{N}$, where $\mathrm{N}=$ maximum number of sunshine hours for given day). Thus, most of the incoming solar radiation reaches ground and $\mathrm{T}_{\max }$ will be larger in relation to T. Lesser clouds during nighttime also result in less downward longwave radiation emitted by the atmosphere and lower $\mathrm{T}_{\min }$ during the night. Solar radiation estimated from 
sunshine hours presented higher values but also with higher variability during the wet season, which relates to the presence of more clouds. Relative humidity decreased along the dry season, while wind speed increased its values until the end of it.

In Figure 3, the coefficient of correlation between ETopM and the meteorological variables used in the HS model by month and by station are presented. Although only TR, $\mathrm{T}$ and Ra are considered in the HS equation, we also presented the correlation to other variables, such as $\mathrm{u}_{2}, \mathrm{RH}$ and Rs, for this would provide better insights on the outcomes from the equation.
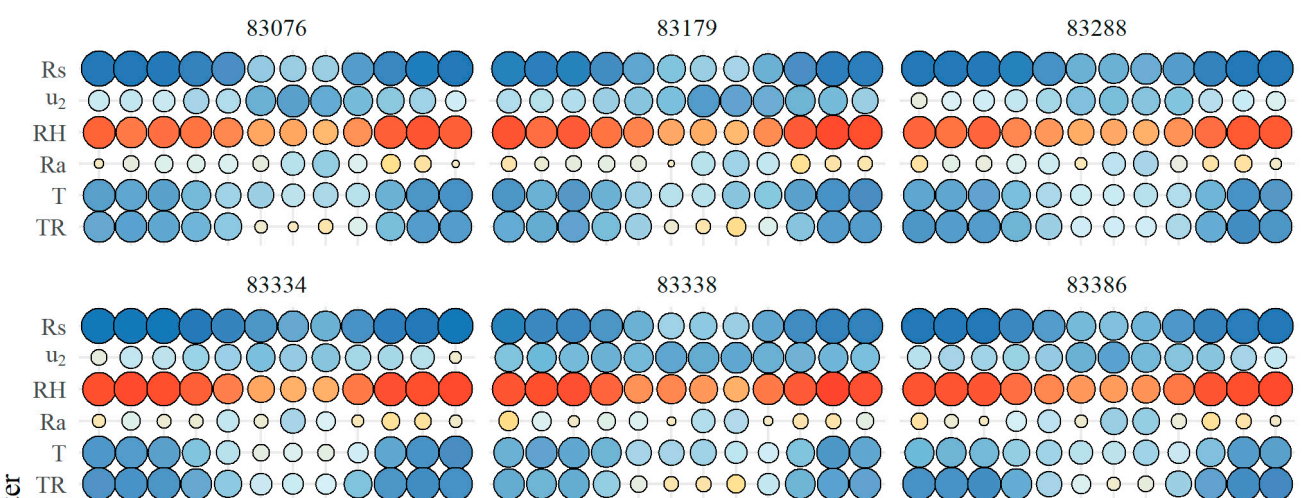

83386

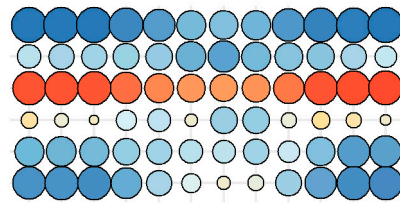

83395

83389

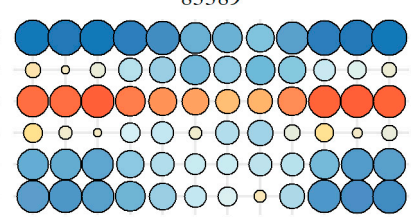

83452
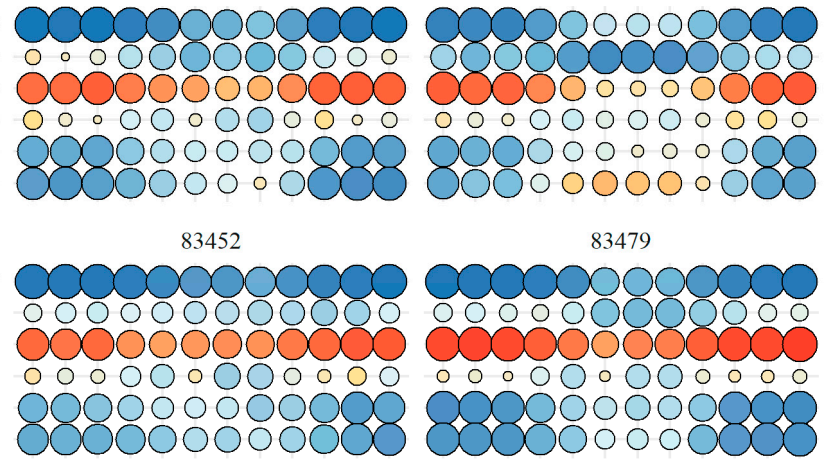

83479

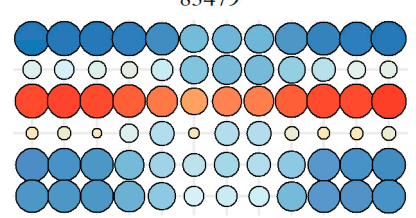

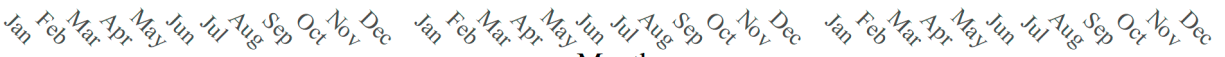

Month

Figure 3. Correlation between Penman-Monteith reference evapotranspiration and meteorological parameters by month and station. Color scale relates to correlation coefficient values, while size scale relates to absolute values of the correlation coefficient.

Monthly-wise, TR and T presented stronger correlations to EToPM during the rainy season, while Ra presented lower correlation in this period. Ra showed larger correlation to ETo ${ }_{\mathrm{PM}}$ during the dry months, from May to August, with an exception for June. It may be noted that the correlations between EToPM and TR, T and Ra decrease during the dry season, while the correlation between EToPM and $\mathrm{u}_{2}$ increases. Even prior to the investigation with the clustering algorithm, the seasonality factor seems to be more relevant than regional.

\subsection{Cluster Analyses}

The total within-cluster sum of squares and average silhouette width from cluster analyses are presented in Figure 4. The meteorological characteristics monthly-wise resulted in better clustering results, which is observed from larger decay in the total within-cluster sum of squares. That is, for the same number of clusters of months and stations, a greater similarity is observed within clusters of months. 

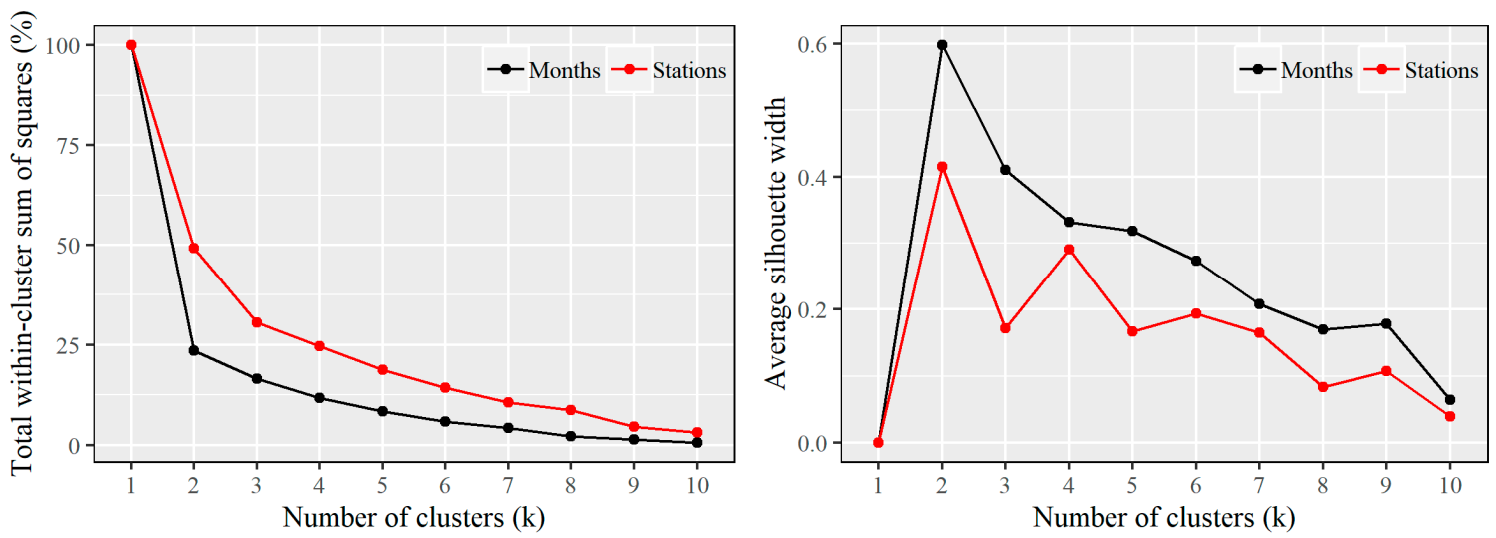

Figure 4. Total within-cluster sum of squares and average silhouette width versus number of clusters (k) while considering meteorological characteristics monthly and station-wise.

As for the optimal number of clusters, adopting the "elbow" method for the total within-cluster sum of squares method could be subjective; however, the average silhouette width method indicates that it would be more effective to partition clusters into two groups-months and stations. Additionally, the higher value of the average silhouette and lower total within-cluster sum of squares indicates that clusters of months are better matched than clusters of stations. Since the Hargreaves-Samani methodology was developed for simplicity, it is appropriate that we adopt two clusters to proceed with the analyses.

While assessing the clustered months considering $\mathrm{k}=2$, approach A2, it is observed that the clustered months coincided with the wet and dry seasons. One cluster contained the months from October to April, and the other from May to September. This confirms that it is adequate to calibrate the Hargreaves-Samani equation considering the wet and dry season, as suggested by Zanetti et al. [24] and Aguilar and Polo [23]. We may also conclude that for regions with similar climatic characteristics, seasonality are stronger indicators of the relation between meteorological variables and evapotranspiration. However, this may not be true for really extensive areas [13].

When $\mathrm{k}=2$ for stations clustering, approach A3, one cluster contained the stations of ID number 83338, 83388 and 83395 (Region One), and the other cluster contained the remaining nine stations (Region Two). The three stations forming Region One are all close together in the eastern region of the middle of the São Francisco Basin (Figure 1). This region is characterized by both the transitions between biomes and climate zones (Figure S1), which resulted in their different behavior when compared to the other stations. Although they are close to regions of humid sub-tropical climate type, their climate seems to be more closely related to a semi-arid one (Caatinga biome), experiencing the lowest rainfall among all stations (Figure S2). A more noticeable characteristic of these stations, however, is the much larger daily wind speed variability and magnitude when compared to the other stations (Figure 5). The higher variability seems to also be the cause for higher correlation between wind speed and ETo throughout the year for these stations (Figure 3). 


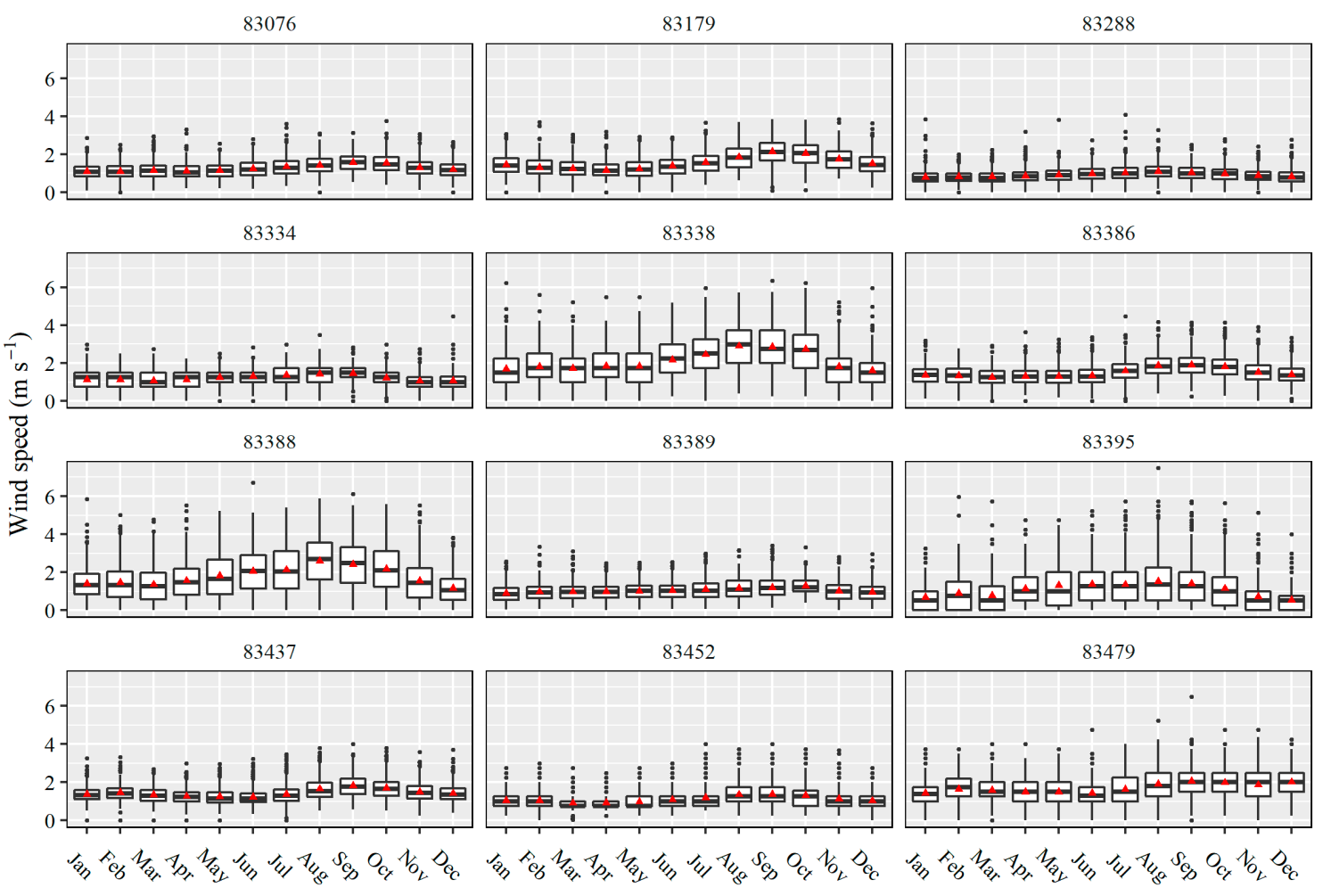

Figure 5. Daily wind speed by month and station.

For approaching A4, the combination of approaches A2 and A3, we separately assessed the clustering of months for Regions One and Two. The total within-cluster sum of squares and average silhouette is presented in Figure 6. In this case, the algorithm showed that the optimal number of clusters of months was also equal to two for both regions. The clusters of months could have been different for each region, however, they are grouped in the same way as in approach A2. That is, a cluster for the dry season (May to September) and another for the wet season (October to April). This only reinforces the belief that rainfall is an important factor determining how ETo interacts with meteorological variables and, therefore, it seems adequate to calibrate the HS equation considering the wet and dry season.
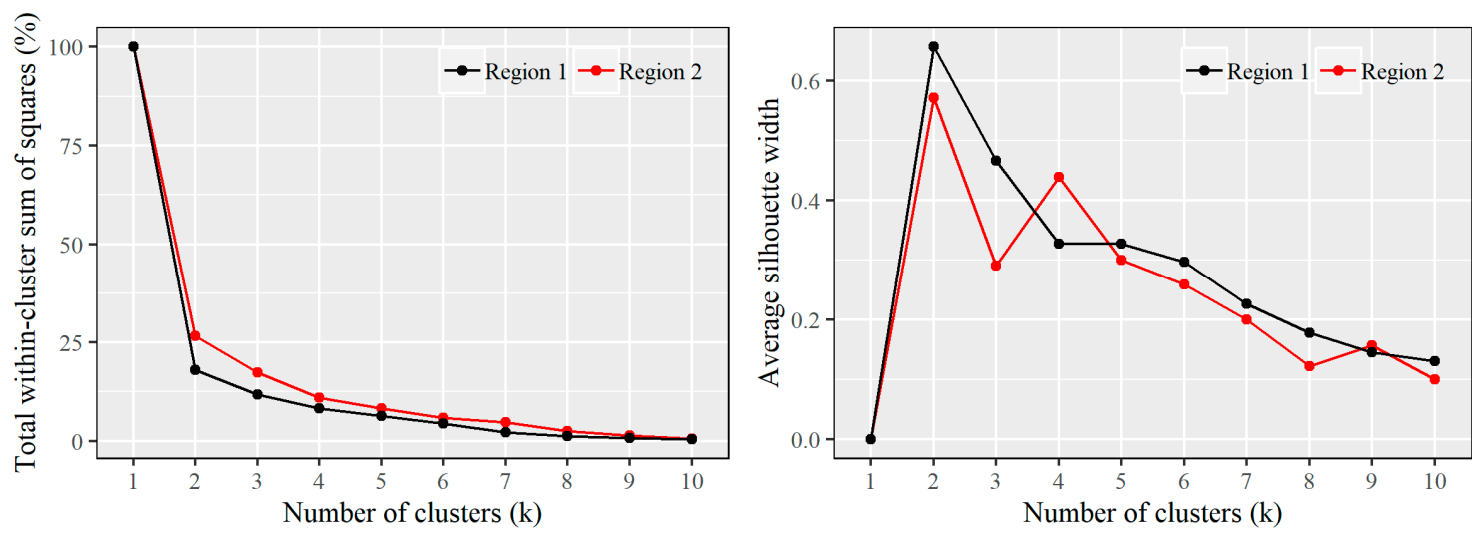

Figure 6. Total within-cluster sum of squares and average silhouette width versus the number of clusters $(k)$ of months while considering their meteorological characteristics for two different regions. 


\subsection{Parameters of Improved Hargreaves-Samani Models}

The four calibration approaches resulted in nine sets of coefficients for the HS equations in the Middle São Francisco River Basin (Table 2). Approach A1 presented one set of coefficients, while A2 and A3 presented two sets of coefficients and A4 presented four sets of coefficients.

Table 2. Summary of coefficients for Hargreaves-Samani equation calibration.

\begin{tabular}{lcc}
\hline \multicolumn{1}{c}{ ETo Models } & $\mathbf{k}_{\mathbf{R s}}$ & Offset \\
\hline Hargreaves and Samani [16] & 0.170 & 17.80 \\
A1-General calibration & 0.166 & 15.30 \\
A2-Clusters by months-wet season & 0.161 & 15.55 \\
A2-Clusters by months-dry season & 0.172 & 15.43 \\
A3-Clusters by region-Region One & 0.175 & 15.88 \\
A3-Clusters by region-Region Two & 0.163 & 15.18 \\
A4-Clusters by region and months-Region One/wet season & 0.168 & 15.79 \\
A4-Clusters by region and months-Region One/dry season & 0.184 & 17.12 \\
A4-Clusters by region and months-Region Two/wet season & 0.159 & 15.49 \\
A4-Clusters by region and months-Region Two/dry season & 0.169 & 15.08 \\
\hline
\end{tabular}

$\mathrm{k}_{\mathrm{Rs}}=$ empirical coefficient of the Hargreaves-Samani equation; offset = mean air temperature offset.

Average $k_{R s}$ observed for the middle São Francisco River Basin was equal to 0.166, just below the standard value used by Hargreaves and Samani [16] (0.170). All offsets from calibrated equations were smaller than the traditional equation, ranging from 15.08 to 17.12 .

We observed higher temperature ranges in the dry season, but lower extraterrestrial solar radiation, resulting in larger $\mathrm{k}_{\mathrm{Rs}}$ for the dry season when compared to the wet season. This is similar to as observed by Paredes et al. [38], where $\mathrm{k}_{\mathrm{Rs}}$ for a diverse number of stations in an archipelago presented lower values for the rainier period.

\subsection{Performances of Improved Hargreaves-Samani Models}

The performance criteria obtained before and after the calibration are presented in Table 3 . The calibration was fundamental in the minimization of errors in ETo estimates, decreasing MAE and RMSE by up to 0.11 and $0.12 \mathrm{~mm} \cdot \mathrm{day}^{-1}$, respectively. The original HS was shown to systematically

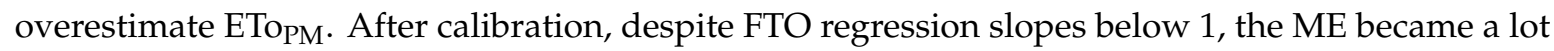
closer to 0 , indicating much lower bias. $\mathrm{R}^{2}$ values only increased for calibration approaches involving clustered data, with a maximum observed value equal to 0.57 .

Table 3. Performance criteria of original and improved Hargreaves-Samani models for the period from 2011 to 2016 (test set).

\begin{tabular}{lccccc}
\hline \multicolumn{1}{c}{ ETo Models } & ME & MAE & RMSE & $\mathbf{R}^{\mathbf{2}}$ & FTO \\
\hline Hargreaves and Samani [16] & 0.37 & 0.76 & 0.96 & 0.53 & 1.05 \\
A1-General calibration & -0.03 & 0.67 & 0.88 & 0.53 & 0.96 \\
A2-Clusters by months & -0.03 & 0.67 & 0.87 & 0.54 & 0.96 \\
A3-Clusters by stations & -0.03 & 0.66 & 0.85 & 0.56 & 0.96 \\
A4-Clusters by stations and months & -0.03 & 0.65 & 0.84 & 0.57 & 0.96 \\
\hline
\end{tabular}

$\overline{\mathrm{ME}}=$ mean bias error $\left(\mathrm{mm} \cdot \mathrm{day}^{-1}\right) ; \mathrm{MAE}=$ mean absolute error $\left(\mathrm{mm} \cdot \mathrm{day}^{-1}\right)$; RMSE = root mean square error $\left(\mathrm{mm} \cdot \mathrm{day}^{-1}\right) ; \mathrm{R}^{2}=$ coefficient of determination; $\mathrm{FTO}=$ slope of the forced to the origin regression.

The performance of the original and improved HS models by month is presented in Tables S1-S5.

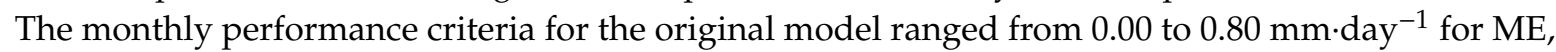
from 0.58 to $1.01 \mathrm{~mm} \cdot \mathrm{day}^{-1}$ for MAE, from 0.73 to $1.19 \mathrm{~mm} \cdot \mathrm{day}^{-1}$ for RMSE, 0.03 to 0.72 for $\mathrm{R}^{2}$ and from 0.98 to 1.11 for the FTO regression slope. The very low values of $\mathrm{R}^{2}$ occurred from May to September and are as a result of the overall poor correlation of TR and T to ETopM (Figure 3). The best performing 
calibration approach, A4, resulted in a decrease in ME of up to $0.55 \mathrm{~mm} \cdot \mathrm{day}^{-1}$; the decrease in MAE ranged from $0.02 \mathrm{~mm} \cdot$ day $^{-1}$, in August and September, to $0.25 \mathrm{~mm} \cdot$ day $^{-1}$, in November.

By clustering data in groups of months, a larger improvement of the predictions was expected. However, the poor correlation of the variables to ETo for the dry season resulted in little performance improvement, e.g., a maximum reduction in RMSE equal to $0.06 \mathrm{~mm} \cdot \mathrm{day}^{-1}$ when compared to approach A1. It is noted in Figure 3 that the parameters with highest correlations to EToPM during the dry season were wind speed, relative humidity and solar radiation, which are not considered in the HS model. Although approach A2 and A4, overall, reduced predictions bias, it resulted in a large increase for the months of August and September, which previously had low biases. On the other hand, approach A3 and A4 resulted in a better balanced bias among the months. Improvements from using approach A3 were superior to those when using approach A2, with a higher overall $R^{2}$. This was not expected at first, since months seemed to group in clusters better than stations did (Figure 4).

As for the stations (Tables S6-S10), the performance of the original HS model by station ranged from -0.52 to $0.90 \mathrm{~mm}$ day $^{-1}$ for ME, 0.54 to $1.00 \mathrm{~mm} \cdot \mathrm{day}^{-1}$ for MAE, from 0.69 to $1.24 \mathrm{~mm} \cdot \mathrm{day}^{-1}$ for RMSE, 0.34 to 0.76 for $\mathrm{R}^{2}$ and from 0.87 to 1.19 for the FTO regression slope. The stations that benefited most for the best performing calibration approach, A4, were stations 83076, 83334, 83452 and 83389, with a decrease in RMSE ranging from 0.28 to $0.35 \mathrm{~mm} \cdot \mathrm{day}^{-1}$. In particular, three stations presented much worse performance, overall, when compared to the rest of them, for which ID numbers are 83338,83388 and 83395 . These three stations coincide with the stations from Region One in approaches A3 and A4. Oddly, stations 83338 and 83388 did not improve the performance for any approach, even decreasing performance for approaches A1 and A2, while station 83395 only slightly improved its performance. In fact, Reis et al. [25] also assessed the HS model for these same three stations and observed no improvements in correlation between observed and predicted values, even when performing the HS model calibration station by station.

It is noted in Figure 5 that all three stations in Region One presented much higher values and variance of wind speed, an important parameter for the aerodynamic term in Penman-Monteith's equation. This alone may be a strong indication that the HS model would not be able to achieve much higher performances after calibration. In addition, stations 83338 and 83388 showed a tendency to underestimate EToPM, while 83395 to overestimate and, perhaps, this opposite behavior hindered the improvement of the region's performance as well. Even for a small region, the very dynamic climatic characteristic of the transition between different biomes and climates rendered the stations different relation to EToPM. This suggests that a single calibration for the HS model in such a dynamic zone will not supply the region's demand for better ETo estimates. For instance, station 83395 is the only station with a large but negative correlation between the temperature range and EToPM during the dry season.

The scatterplots for the test set predictions using the single equation calibrated for the MSFB (A1) and the best calibration approach (A4) are shown in Figures 7 and 8 for each station. It may be noted that, for all cases, the fitted line indicates the improved HS method generally overestimates lower values of ETo, while generally underestimating higher values. This behavior is aggravated for the stations that performed worse (83338, 83388 and 83395). A similar behavior has also been observed while reviewing many studies regarding the HS methodology $[24,38,39]$. For not considering all input variables in the ETo estimation, the HS model is less prone to extreme values and makes predictions in smaller ranges. Therefore, the OLS fitted line becomes more horizontal and its estimates are closer to the observed mean, thereby decreasing the determination coefficient of the fitted model.

By comparing Figures 7 and 8, a larger improvement is noted for stations 83338 and 83388 from A1 to A4. Oddly, station 83395 showed a decrease in performance upon comparing A1 to A4. In fact, by pooling all the data in approach A1, we improved the performance of most stations, but severely decreased the performance for 83338 and 83388 . This is likely an outcome from stations 83338 and 83388 not only presenting high wind speed variability, but also higher daily values, resulting in the original model underestimating EToPM for these stations. In Region One, although the stations' high 
wind speed variability resulted in a similar correlation to $\mathrm{ETo}_{\mathrm{PM}}$, lower values of wind speed for station 83395 resulted in a tendency to overestimate $\mathrm{ETo}_{\mathrm{PM}}$, similar to the stations in Region Two.

Despite the meteorological spatial variability had proven itself significant, the calibration for Region One using approach A4 showed close to no improvement when compared to the original HS equation. On the other hand, the performance improvement from Region Two was very similar to what is observed in approach A1. This indicates that approach A1 is likely the best option, and an alternative would be to not include stations with similar characteristics to Region One in the calibration, as their performance seems to rely on more complex models. Perhaps, performing calibrations using a larger number of cluster of stations, or station by station, could lead to better results in this region. However, this would have resulted in obtaining far more equations for the middle of São Francisco and deviate from the original purpose of the HS model—simplicity. In addition, each equation would be very specific for very small regions and not convenient overall.

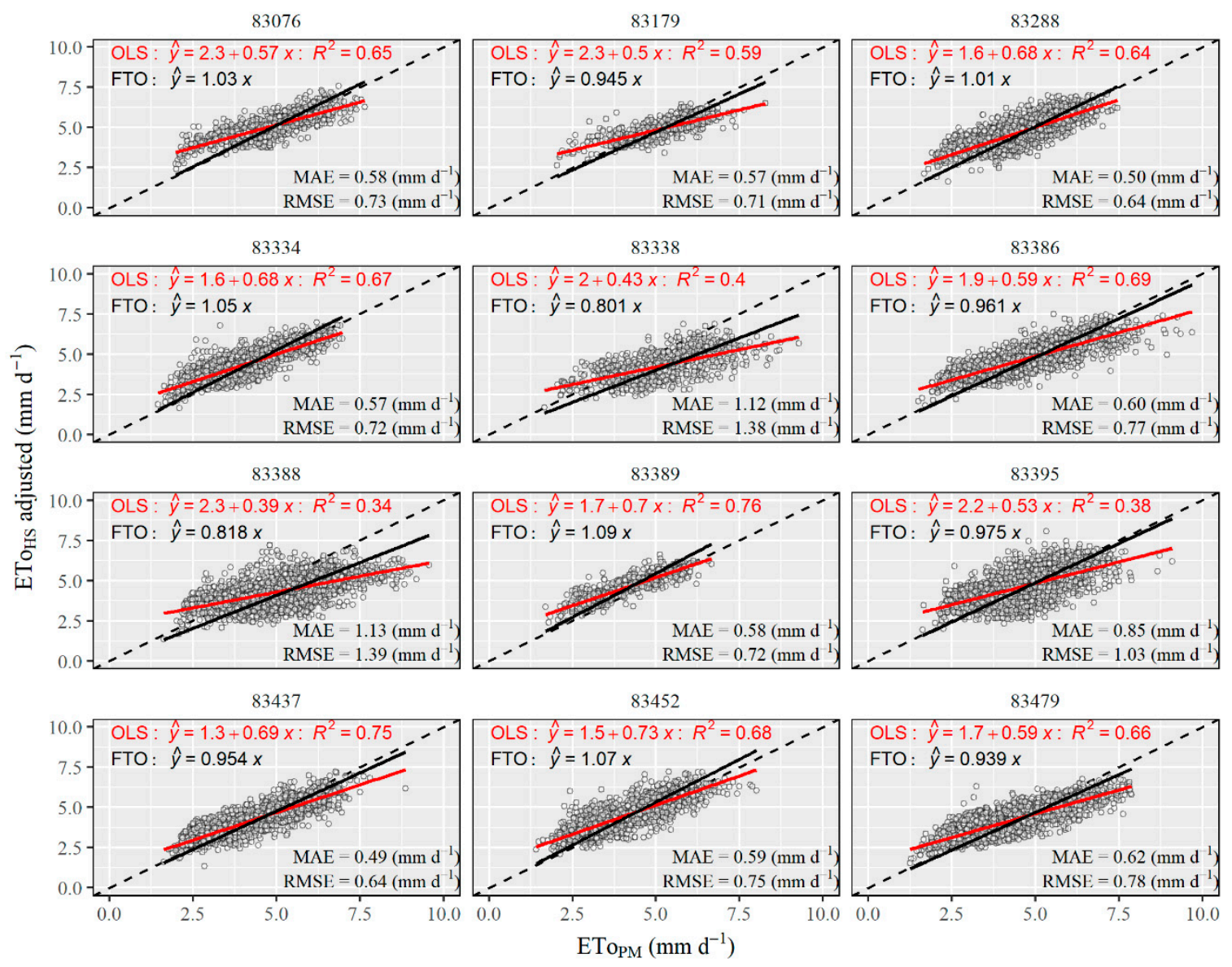

Figure 7. Daily reference evapotranspiration scatterplots between Penman-Monteith and Hargreaves-Samani improved by fitting new coefficients (approach A1). The red and black lines are the ordinary least squares (OLS) and forced to the origin (FTO) regressions. 
83076

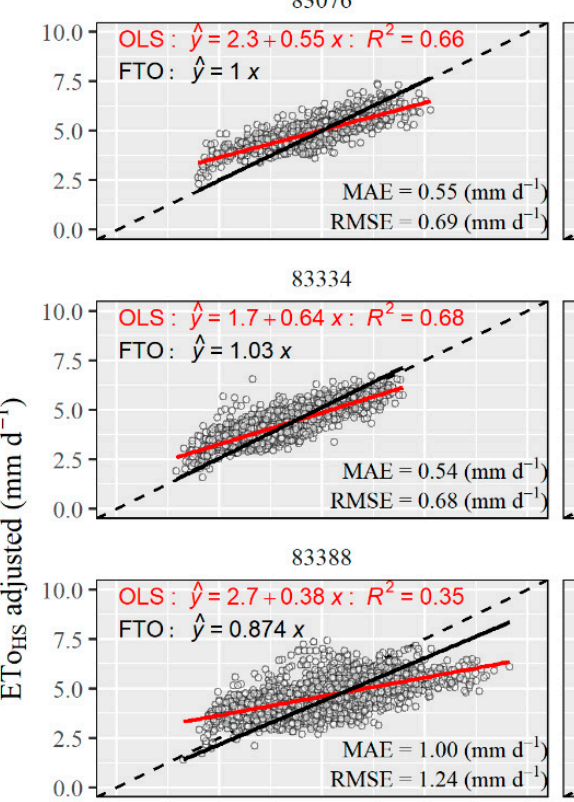

83437

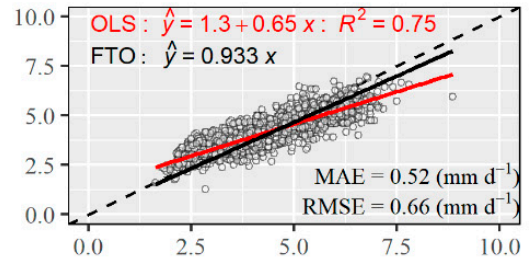

83179

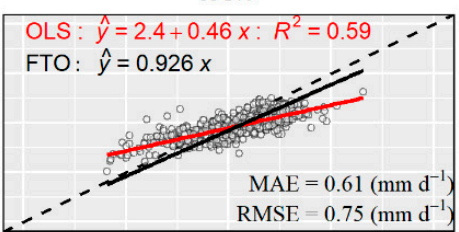

83338

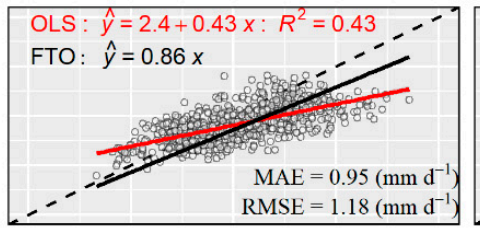

83389

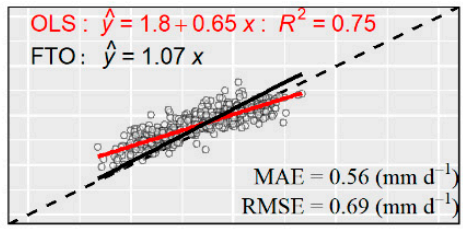

83452

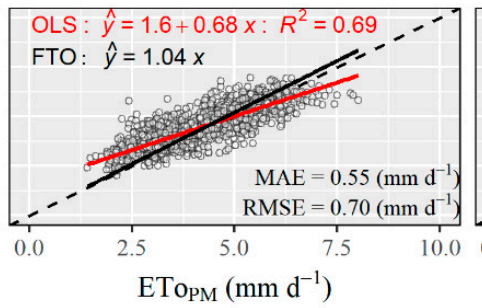

83288

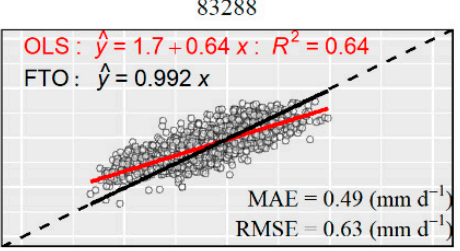

83386

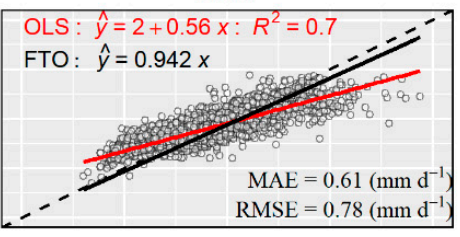

83395

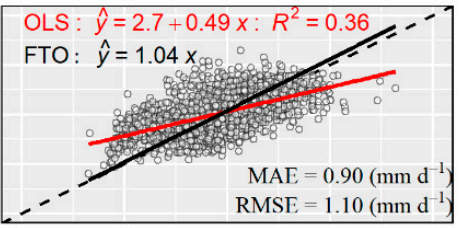

83479

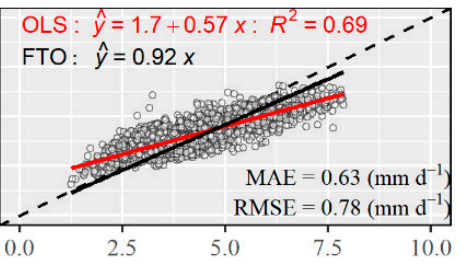

Figure 8. Daily reference evapotranspiration scatterplots between Penman-Monteith and Hargreaves-Samani improved by clustering data by stations and months (approach A4). The red and black lines are the ordinary least squares (OLS) and forced to the origin (FTO) regressions.

Zhu et al. [39] evaluated the original HS and its calibrated form for 838 weather stations in China, and also observed that the HS model accuracy generally decreases in conditions of extreme values because the model ignores relative humidity and wind speed. For humid regions, however, Paredes et al. [38] documented that wind impacts are unimportant for the HS model, but require proper adjustments. To surpass the limitations that the absence of wind speed may impose in tropical and semiarid regions, Cobaner et al. [11] assessed a modified version of the HS model for 275 weather stations in Turkey. The authors modified version included the wind speed in the equation, resulting in better accuracy for all stations. Similarly, Valiantzas [40] developed new equations, including relative humidity alone or in addition to wind speed. Considering 32 stations in California, Florida, Arizona and Greece, the author documented an improved accuracy of about $45 \%$ by including relative humidity alone.

Overall, we may conclude that finding periods or regions with similar climatic conditions is important to calibrate the HS model and, generally, results in better performances, but does not necessarily mean that predictions for a given period of the year or region will largely benefit from it. In the case of the middle of São Francisco, (i) a single equation for the entire region and year (approach A1) is a clear improvement on the Davis-calibrated HS equation. (ii) Improvements from further seasonal/regional calibrations were small and seem to be unjustified. The performance of predictions showed stronger dependency on the correlation between input and output variables used in the model. Thus, (iii) the use of the full PM equation, or at least more complex models, seems to be unavoidable for the dry season, when the HS model variables presented lower correlation to $\mathrm{ETo}_{\mathrm{PM}}$, and for Region 
One, where wind speed presents high variability throughout the year. In those situations, the models developed for a region should be assessed carefully.

\section{Conclusions}

In this paper, we investigate the effects of local calibration of the Hargreaves-Samani equation for estimating reference evapotranspiration in the middle portion of the São Francisco River Basin (MSFB). The calibration approaches used considered a single calibration for the entire MSFB and year, a calibration for clusters of months, a calibration for clusters of stations and a calibration for the contexts resulted by clustering months within sub-regions. In order to cluster data, an algorithm of unsupervised learning was used by considering the correlations between meteorological variables and reference evapotranspiration.

The meteorological data from the MSFB were shown to be more effectively segregated by their seasonal similarities, as opposed to regional similarities. The clustered months coincided with the wet and dry seasons; however, the improvement of the HS model predictions did not depend only on finding similar regions. We observed that the mean air temperature and the range between the daily maximum and minimum showed a poor correlation to reference evapotranspiration during the dry season, resulting in only a small improvement on the performance by the calibration for the period.

When clustering data by stations, the clustering algorithm indicated that the optimal number of clusters was two sub-regions. Yet, the cluster with stations located in the eastern region of the middle São Francisco River Basin presented a poor performance by the HS model for all approaches assessed. The cause for this is that the region presents higher variability in terms of the wind speed values, which the model is not sensitive to. In addition, stations within this small region presented different bias behavior when predicting EToPM.

The HS model is one of the most parsimonious and widely used equations for data-scarce regions, and its calibration is fundamental for reducing bias and making more adequate evapotranspiration predictions. In summary, the results suggest that the use of a single HS equation calibrated for the MSFB region is a clear improvement on the original equation, and further calibrations by season or region seem unjustified. Lower correlation between meteorological variables used in the model and reference evapotranspiration during the dry season and high wind speed variability for stations indicate that the use of the full PM equation is necessary.

Supplementary Materials: The following are available online at http://www.mdpi.com/2073-4441/11/11/2272/s1, Figure S1: Weather stations in relation to climate zones and biomes, Figure S2. Monthly rainfall by month and station, Figure S3. Daily reference evapotranspiration by month and station, Figure S4. Daily solar radiation by month and station, Figure S5. Daily relative humidity by month and station, Figure S6. Daily wind speed by month and station, Figure S7. Daily mean air temperature by month and station, Figure S8. Daily temperature range by month and station, Table S1: Performance by month of reference evapotranspiration predictions made by the Hargreaves-Samani model, Table S2. Performance by month of reference evapotranspiration predictions made by the Hargreaves-Samani model calibrated with approach A1, Table S3. Performance by month of reference evapotranspiration predictions made by the Hargreaves-Samani model calibrated with approach A2, Table S4. Performance by month of reference evapotranspiration predictions made by the Hargreaves-Samani model calibrated with approach A3, Table S5. Performance by month of reference evapotranspiration predictions made by the Hargreaves-Samani model calibrated with approach A4, Table S6. Performance by station of reference evapotranspiration predictions made by the Hargreaves-Samani model, Table S7. Performance by station of reference evapotranspiration predictions made by the Hargreaves-Samani model calibrated with approach A1, Table S8. Performance by station of reference evapotranspiration predictions made by the Hargreaves-Samani model calibrated with approach A2, Table S9. Performance by station of reference evapotranspiration predictions made by the Hargreaves-Samani model calibrated with approach A3, Table S10. Performance by station of reference evapotranspiration predictions made by the Hargreaves-Samani model calibrated with approach A4.

Author Contributions: Formal analysis, D.A.; methodology, D.A. and R.A.d.S.; writing-original draft, D.A. and R.A.d.S.; writing-review and editing, H.C.B., F.F.d.C. and R.F.

Funding: This study was supported by the Federal University of Viçosa-UFV, the National Council for Scientific and Technological Development-CAPES (grant number-142273/2019-8) and by the Coordination for the Improvement of Higher Education Personnel-CAPES (finance code 001).

Conflicts of Interest: The authors declare no conflict of interest. 


\section{References}

1. Abdulbaki, D.; Al-Hindi, M.; Yassine, A.; Abou Najm, M. An optimization model for the allocation of water resources. J. Clean. Prod. 2017, 164, 994-1006. [CrossRef]

2. Wendt, D.E.; Rodrigues, L.N.; Dijksma, R.; Van Dam, J.C. Assessing groundwater potential use for expanding irrigation in the Buriti Vermelho watershed. IRRIGA 2015, 1, 81-94. [CrossRef]

3. Silva, J.M.D.; Gurgel, I.G.D.; Santos, M.O.D.; Gurgel, A.D.M.; Augusto, L.G.D.S.; Costa, A.M. Conflitos ambientais e as águas do rio São Francisco. Saúde E Soc. 2015, 24, 1208-1216. [CrossRef]

4. Getirana, A.C.V.; de Fátima Malta, V.; de Azevedo, J.P.S. Decision Process in a Water Use Conflict in Brazil. Water Resour. Manag. 2008, 22, 103-118. [CrossRef]

5. Zohaib, M.; Kim, H.; Choi, M. Detecting global irrigated areas by using satellite and reanalysis products. Sci. Total Environ. 2019, 677, 679-691. [CrossRef]

6. Godfray, H.C.J.; Beddington, J.R.; Crute, I.R.; Haddad, L.; Lawrence, D.; Muir, J.F.; Pretty, J.; Robinson, S.; Thomas, S.M.; Toulmin, C. Food security: The challenge of feeding 9 billion people. Science 2010, 327, 812-818. [CrossRef]

7. Tarjuelo, J.M.; Rodriguez-Diaz, J.A.; Abadía, R.; Camacho, E.; Rocamora, C.; Moreno, M.A. Efficient water and energy use in irrigation modernization: Lessons from Spanish case studies. Agric. Water Manag. 2015, 162, 67-77. [CrossRef]

8. Jiménez-Bello, M.A.; Royuela, A.; Manzano, J.; Prats, A.G.; Martínez-Alzamora, F. Methodology to improve water and energy use by proper irrigation scheduling in pressurised networks. Agric. Water Manag. 2015, 149, 91-101. [CrossRef]

9. Pryor, S.W.; Smithers, J.; Lyne, P.; van Antwerpen, R. Impact of agricultural practices on energy use and greenhouse gas emissions for South African sugarcane production. J. Clean. Prod. 2017, 141, 137-145. [CrossRef]

10. Allen, R.G.; Pereira, L.S.; Raes, D.; Smith, M. Crop Evapotranspiration-Guidelines for Computing Crop Water Requirements-FAO Irrigation and Drainage Paper 56, 9th ed.; Food and Agriculture Organization of the United Nations: Rome, Italy, 1998; ISBN 92-5-104219-5.

11. Cobaner, M.; Citakoğlu, H.; Haktanir, T.; Kisi, O. Modifying Hargreaves-Samani equation with meteorological variables for estimation of reference evapotranspiration in Turkey. Hydrol. Res. 2017, 48, 480-497. [CrossRef]

12. Dou, X.; Yang, Y. Evapotranspiration estimation using four different machine learning approaches in different terrestrial ecosystems. Comput. Electron. Agric. 2018, 148, 95-106. [CrossRef]

13. Ferreira, L.B.; da Cunha, F.F.; de Oliveira, R.A.; Fernandes Filho, E.I. Estimation of reference evapotranspiration in Brazil with limited meteorological data using ANN and SVM-A new approach. J. Hydrol. 2019, 572, 556-570. [CrossRef]

14. Tabari, H.; Grismer, M.E.; Trajkovic, S. Comparative analysis of 31 reference evapotranspiration methods under humid conditions. Irrig. Sci. 2013, 31, 107-117. [CrossRef]

15. ASCE-EWRI. The ASCE standardized reference evapotranspiration equation. In Technical Committee Rep. to the Environmental and Water Resources Institute of ASCE from the Task Committee on Standardization of Reference Evapotranspiration; ASCE-EWRI: Reston, VA, USA, 2005; p. 173.

16. Hargreaves, G.H.; Samani, Z.A. Reference crop evapotranspiration from temperature. Appl. Eng. Agric. 1985, 1, 96-99. [CrossRef]

17. Gavilán, P.; Lorite, I.J.; Tornero, S.; Berengena, J. Regional calibration of Hargreaves equation for estimating reference ET in a semiarid environment. Agric. Water Manag. 2006, 81, 257-281. [CrossRef]

18. Shiri, J.; Sadraddini, A.A.; Nazemi, A.H.; Marti, P.; Fakheri Fard, A.; Kisi, O.; Landeras, G. Independent testing for assessing the calibration of the Hargreaves-Samani equation: New heuristic alternatives for Iran. Comput. Electron. Agric. 2015, 117, 70-80. [CrossRef]

19. Tabaru, H.; Talaee, P.H. Local Calibration of the Hargreaves and Priestley-Taylor Equations for Estimating Reference Evapotranspiration in Arid and Cold Climates of Iran Based on the Penman-Monteith Model. J. Hydrol. Eng. 2011, 16, 837-845. [CrossRef]

20. Zhang, Q.; Cui, N.; Feng, Y.; Gong, D.; Hu, X. Improvement of Makkink model for reference evapotranspiration estimation using temperature data in Northwest China. J. Hydrol. 2018, 566, 264-273. [CrossRef]

21. Mendicino, G.; Senatore, A. Regionalization of the Hargreaves Coefficient for the Assessment of Distributed Reference Evapotranspiration in Southern Italy. J. Irrig. Drain. Eng. 2013, 139, 349-362. [CrossRef] 
22. Ravazzani, G.; Corbari, C.; Morella, S.; Gianoli, P.; Mancini, M. Modified Hargreaves-Samani Equation for the Assessment of Reference Evapotranspiration in Alpine River Basins. J. Irrig. Drain. Eng. 2012, 138, 592-599. [CrossRef]

23. Aguilar, C.; Polo, M.J. Generating reference evapotranspiration surfaces from the Hargreaves equation at watershed scale. Hydrol. Earth Syst. Sci. 2011, 15, 2495-2508. [CrossRef]

24. Zanetti, S.S.; Dohler, R.E.; Cecílio, R.A.; Pezzopane, J.E.M.; Xavier, A.C. Proposal for the use of daily thermal amplitude for the calibration of the Hargreaves-Samani equation. J. Hydrol. 2019, 571, 193-201. [CrossRef]

25. Reis, M.M.; da Silva, A.J.; Zullo Junior, J.; Tuffi Santos, L.D.; Azevedo, A.M.; Lopes, É.M.G. Empirical and learning machine approaches to estimating reference evapotranspiration based on temperature data. Comput. Electron. Agric. 2019, 165, 104937. [CrossRef]

26. Liou, Y.-A.; Kar, S.K. Evapotranspiration Estimation with Remote Sensing and Various Surface Energy Balance Algorithms-A Review. Energies 2014, 7, 2821-2849. [CrossRef]

27. Alvares, C.A.; Stape, J.L.; Sentelhas, P.C.; de Moraes, G.; Leonardo, J.; Sparovek, G. Köppen's climate classification map for Brazil. Meteorol. Z. 2013, 22, 711-728. [CrossRef]

28. Pousa, R.; Costa, M.H.; Pimenta, F.M.; Fontes, V.C.; Brito, V.F.A.D.; Castro, M. Climate change and intense irrigation growth in western Bahia, Brazil: The urgent beed for hydroclimatic monitoring. Water 2019, 11, 933. [CrossRef]

29. Filgueiras, R.; Reis, M.M.; Lopes, É.M.G.; Ribeiro, R.B.; Ramos, M.C.A. Spatio-temporal dynamics of climatological variables in the aid of decision making for irrigated agriculture. J. Agric. Sci. 2019, 11, 292. [CrossRef]

30. EMBRAPA. Relatório técnico e de atividades da Embrapa Semiárido 2011. In Technical Report and Activities from the Semiarid Embrapa 2011; Embrapa Semiárido: Petrolina, Brazil, 2012; p. 69. (In English)

31. Shafer, M.A.; Fiebrich, C.A.; Arndt, D.S.; Fredrickson, S.E.; Hughes, T.W. Quality assurance procedures in the Oklahoma mesonetwork. J. Atmos. Ocean. Technol. 2000, 17, 474-494. [CrossRef]

32. Gavilán, P.; Estévez, J.; Berengena, J. Comparison of standardized reference evapotranspiration equations in Southern Spain. J. Irrig. Drain. Eng. 2008, 134, 1-12. [CrossRef]

33. Estévez, J.; Gavilán, P.; Giráldez, J.V. Guidelines on validation procedures for meteorological data from automatic weather stations. J. Hydrol. 2011, 402, 144-154. [CrossRef]

34. Hargreaves, G.H.; Samani, Z.A. Estimating potential evapotranspiration. J. Irrig. Drain. Div. 1982, 108, 225-230.

35. Hartigan, J.A.; Wong, M.A. Algorithm AS 136: A K-Means Clustering Algorithm. J. R. Stat. Soc. Ser. C Appl. Stat. 1979, 28, 100-108. [CrossRef]

36. Charrad, M.; Ghazzali, N.; Boiteau, V.; Niknafs, A. NbClust: An R Package for Determining the Relevant Number of Clusters in a Data Set. J. Stat. Softw. 2014, 61, 1-36. [CrossRef]

37. Bholowalia, P.; Kumar, A. EBK-means: A clustering technique based on elbow method and k-means in WSN. Int. J. Comput. Appl. 2014, 105, 17-24.

38. Paredes, P.; Fontes, J.C.; Azevedo, E.B.; Pereira, L.S. Daily reference crop evapotranspiration in the humid environments of Azores islands using reduced data sets: Accuracy of FAO-PM temperature and Hargreaves-Samani methods. Theor. Appl. Climatol. 2018, 134, 595-611. [CrossRef]

39. Zhu, X.; Luo, T.; Luo, Y.; Yang, Y.; Guo, L.; Luo, H.; Fang, C.; Cui, Y. Calibration and Validation of the Hargreaves-Samani Model for Reference Evapotranspiration Estimation in China. Irrig. Drain. 2019, 68, 822-836. [CrossRef]

40. Valiantzas, J.D. Temperature-and humidity-based simplified Penman's ET0 formulae. Comparisons with temperature-based Hargreaves-Samani and other methodologies. Agric. Water Manag. 2018, 208, 326-334. [CrossRef]

(C) 2019 by the authors. Licensee MDPI, Basel, Switzerland. This article is an open access article distributed under the terms and conditions of the Creative Commons Attribution (CC BY) license (http://creativecommons.org/licenses/by/4.0/). 